\title{
COVID-19 Vaccine Acceptance: Beliefs and Barriers Associated with Vaccination Among the Residents of KSA
}

\author{
Bayapa \\ Reddy Narapureddy (D) \\ Khursheed Muzammil' \\ Mohammad Yahya Alshahrani ${ }^{2}$ \\ Ali G Alkhathami ${ }^{2}$ \\ Abdullah Alsabaani ${ }^{3}$ \\ Abdullah M AlShahrani (iD ${ }^{4}$ \\ Adam Dawria' \\ Nazim Nasir ${ }^{4}$ \\ Lingala Kalyan Viswanath \\ Reddy $^{5}$ \\ Mohammad Mahtab Alam ${ }^{6}$ \\ 'Department of Public Health, College of \\ Applied Medical Sciences, Khamis Mushayt, \\ King Khalid University, Abha, 6256I, \\ Kingdom of Saudi Arabia; ${ }^{2}$ Department of \\ Clinical Laboratory Sciences, College of \\ Applied Medical Sciences, Abha, King \\ Khalid University, Abha, 9088, Kingdom of \\ Saudi Arabia; ${ }^{3}$ Department of Family and \\ Community Medicine, College of Medicine, \\ King Khalid University, Abha, Saudi Arabia; \\ ${ }^{4}$ Department of Basic Medical Sciences, \\ College of Applied Medical Sciences, \\ Khamis Mushayt, King Khalid University, \\ Abha, 6256I, Kingdom of Saudi Arabia; \\ ${ }^{5}$ Department of Public Health, College of \\ Health Sciences, Saudi Electronic \\ University, Abha, 6256I, Kingdom of Saudi \\ Arabia; ${ }^{6}$ Department of Basic Medical \\ Sciences, College of Applied Medical \\ Science, Abha, King Khalid University, \\ Abha, 6256I, Kingdom of Saudi Arabia
}

Correspondence: Bayapa Reddy Narapureddy

Department of Public Health, College of Applied Medical Sciences, Khamis Mushayt, King Khalid University, Abha, 6256I, Kingdom of Saudi Arabia Tel +966-557I4527

Email bapureddy@kku.edu.sa
Introduction: COVID-19 was declared a pandemic in March 2020 by the World Health Organization. Control of COVID-19 depends on the potential vaccine and its successful delivery to a large portion of the population to develop herd immunity. All the governments have made a robust plan to distribute the vaccine to their people, but many countries could not achieve adequate vaccination coverage. Hence, this study explores people's beliefs and barriers to vaccination and provides valuable inputs to the government to attain adequate vaccination.

Objective: To know the knowledge level about the COVID-19 vaccine among the residents of KSA. To find out the various concerns (beliefs) about COVID-19 and its vaccine among the residents of KSA. To estimate the vaccine acceptance and understand the barriers to accepting the COVID-19 vaccine among residents of KSA.

Materials and Methods: A web-based, cross-sectional study was conducted from April to June 2021 in a restricted environment on the adult ( $>18$ years) residents of Saudi Arabia. The minimum calculated sample was $685 ; 796$ study samples were finally studied to minimize the sampling error. Snowball sampling was used to select the study samples, after meeting the inclusion criteria.

Results: A total of 796 people responded. Only 782 (98.2\%) were finally considered after excluding the incomplete information forms. The selected participant's age ranges from 18 years to 80 years. Almost 723 (92\%) of the study group knew COVID vaccines. Most of the participants, 370 (47\%), preferred USA-manufactured vaccine followed by Saudi Arabia 217 (28\%). A total of 259 (33.1\%) participants were hesitant to receive the vaccine. Out of 782 , half of the participants, $386(50 \%)$, believed the COVID vaccine will prevent the infection. Conclusion: The government must implement appropriate culturally accepted interventional vaccination educational campaigns to remove the beliefs, worries regarding the safety and efficacy of COVID-19 vaccines, to increase vaccine acceptance rates.

Keywords: COVID-19, public willingness, vaccine, vaccine hesitancy, vaccine acceptance, Saudi Arabia

\section{Introduction}

In China, the Wuhan city of Hubei province reported a considerable number with the exponential increase of new cases with symptoms of fever, cough, and breathlessness. These symptoms ranged from none to very severe life-threatening. ${ }^{1}$ Later, the reason for these symptoms was linked to the coronavirus on February 11, 2020. WHO named it has COVID-19 caused by a coronavirus (SARS-CoV-2); this declared the COVID-19 outbreak a Public Health Emergency of International 
Concern in January 2020 and a pandemic in March 2020 by the World Health Organization. ${ }^{2}$ This COVID-19 pandemic has caused a heavy burden of morbidity and mortality and economic tumult around the Globe. COVID-19 has reached almost 227 countries across the Globe, affected more than 200 million population, and killed nearly 4.3 million people worldwide. Although the first case was reported a year ago, there is no definite antiviral treatment for COVID-19. ${ }^{3}$ Several scientists in the recent past repurposed several drugs for the COVID-19 management. Some have shown slight effectiveness in reducing mortality, but the morbidity and incidence of the cases were unchanged. Long-term COVID-19 control will depend on the potential vaccine and its successful delivery to a large portion of the population to prevent and control COVID-19. ${ }^{4}$ The containment of the ongoing community spread of COVID-19 is only possible with adequate vaccine coverage to develop herd immunity within the community. Immunization is one of the most successful and cost-effective health interventions to prevent infectious diseases. The vaccines against COVID-19 are of great importance to avoid disease morbidity and mortality. ${ }^{5}$

The Strategic Advisory Group of Experts (SAGE) Working Group on Vaccine Hesitancy has defined vaccine hesitancy as "delay in acceptance or refusal of vaccines despite availability of vaccine services". 6 As per the WHO, the reluctance or refusal to vaccinate threatens the progress made in tackling vaccine-preventable diseases, and it is 1 of the top 10 public health problems in the world.

The government has made a robust plan to distribute to their public at the earliest to control this COVID-19 pandemic. Through mass media and non-governmental agencies like the WHO, the governments are continuously working to build vaccine literacy among the public to accept the vaccine when it is available and appropriate. Anti-vaccination activists are already campaigning in multiple countries against the need for a vaccine. Some are denying the vaccine because of the nonexistence of COVID-19 altogether. ${ }^{7}$

\section{Need for the Study}

The reluctance or refusal to vaccination despite the availability of the COVID-19 vaccine will threaten to reverse progress made in tackling the coronavirus disease 2019 (COVID-19) diseases. This study intends to find out the perceptions, beliefs, and barriers associated with the COVID-19 vaccination. In addition, the current study will find out the psychological, social, and political behaviour of the individual towards a COVID-19 vaccine. Finally, this study will provide insight to the administrators and program managers to improve vaccine coverage in the country. ${ }^{8}$ Hence, this study aimed to provide inputs to the government in tackling the COVID-19 pandemic, with the following objectives.

\section{Objectives}

1. To know the knowledge level about COVID-19 vaccine among the residents of KSA

2. To find out the various concerns (beliefs) about COVID-19 and its vaccine among the residents of KSA

3. To estimate the vaccine acceptance and to understand the barriers to accepting the COVID-19 vaccine among residents of KSA

\section{Methodology}

A cross-sectional study that was web-based conducted from April to June 2021 in a restricted environment on the adult ( $>18$ years) residents of Saudi Arabia. This study was planned through online mode because Saudi Arabia currently has a total population of 35.08 million. Moreover, 27.08 million (79.25\%) of the population are active social media users. ${ }^{9}$ This study primarily focused on the literate individuals who are willing to participate and able to read and write either English or Arabic and having internet access was included. The sample size calculation was based on the previous study conducted in Saudi Arabia. The acceptance rate was $64.7 \% .^{10}$ The sample size was calculated using the $4 \mathrm{pq} / \mathrm{d}^{2}$ formula: $4 \times 64.7 \times 35.3 / 4 \times 4=571$. The minimum calculated sample was 571 of this calculated sample size; $20 \%$ (114) considered as non-response or incomplete submission in total (685) subjects must be studied. To minimize the sampling error we finally studied 796 samples. Study samples were selected using snowball sampling after meeting the following inclusion criteria: age greater than 18 years, residing in the KSA, and willing to give informed consent to participate in the study.

\section{Study Tool}

The basic outline of the study is to prepare the validated self-administered electronic study tool. The tool was adapted from previous studies with modifications validated by three independent research experts. ${ }^{11,12}$ The study tool was prepared in the English language, translated to local 
language Arabic, and back-translated to check the validity of the translation. The study instrument was divided into five major sections to collect the data in section one. The consent for the study; the second section was socio-demographic details of the participants, the third section regarding the general information includes the weight, height, habits, any history of allergy, and any chronic illness or physical impairment of the study subjects in section four concentrated on the Beliefs on COVID-19 of the study group, and in section five COVID-19 vaccine acceptance, and barriers preventing to get vaccinated. The self-administered online survey electronic study tool was made in Google Forms and circulated through social media sites, such as WhatsApp, Facebook, Twitter, etc.

\section{Statistical Analysis}

All the collected data were downloaded from Google forms in the MS office 2019 Excel spreadsheet. The data are then validated and analyzed using Statistical Package for the Social Sciences (SPSS) version 21 for windows (SPSS Inc, Chicago, IL, USA). Qualitative variables expressed in proportions and chi square and other appropriate tests were applied to test the hypothesis. The data were analyzed at the $95 \%$ confidence interval level, where a p-value of $<0.05$ was considered significant.

\section{Ethical Approval}

This study was conducted in accordance with the Declaration of Helsinki. The informed consent was obtained prior to participating in the study. Institutional Ethical approval was obtained from the Research Ethics Committee at King Khalid University (HAPO-06-B-001) Abha Kingdom of Saudi Arabia (ECM\#2020-3311).

\section{Results}

A total of 796 people responded; out of these responses, only $782(98.2 \%)$ were finally considered for the analysis after excluding the incomplete information forms.

The survey reached a population ranging from 18 to 80 years with a mean age of 35.08 years ( \pm 10.13 years). Of the 782 respondents, $276(35.3 \%)$ were women, and 506 (64.7\%) were men. Most of the respondents, 752 (96.1\%), were Saudi nationals, and very few 30 (3.9\%) were nonSaudi Nationals, three-fourth of the participants, 549 $(70.9 \%)$, were married, followed by one-third of the responders were unmarried $228(29.1 \%)$, and the remaining $5(0.6 \%)$ were either widows or separated. More than half of the respondents, $444(56.7 \%)$, completed their graduation, one-quarter of the respondents were postgraduates and above 202 (25.8\%), and the remaining studied up to High school or less $136(17.4 \%)$. Many of the responders lived in urban areas 683 (87.3\%), and the remaining were rural $99(12.7 \%)$. The socio-demographic information is tabulated in Table 1.

Out of 752 Saudi respondents, 259 (34.4\%) were not willing (hesitance) to take COVID-19 vaccine. Among the vaccine hesitance group, $124(47.8 \%)$ of them were females and around one-quarter 135 (52.1\%) of them were males, the difference between these were statistically significant $(\mathrm{p}<0.0001)$. Nearly $40 \%$ of the middle-aged (40-59 years) responders were not interested to intend the vaccine; the difference between age groups to accept the vaccine was statistically significant $(\mathrm{p}<0.007)$. All the levels of educated responders showed a similar type of hesitancy towards vaccination. The multivariate analysis showed the education is the significant potential factor for accepting the vaccine. The urban population showed more unwillingness than the rural population to accept the vaccine. Those responders with chronic diseases expressed their negativism towards COVID-19 vaccine. This might be due to the fear of side effects and lack of evidence on the vaccine efficacy. Further details have been provided in Table 2.

Of the study participants, nearly half of them expressed that the risk of getting COVID in near future is high [124 (16\%) was strongly agreed, and 280 (36\%) were agreed], where $103(13 \%)$ were firmly disagreed this statement. The difference was statistically significant $(\mathrm{p}<0.001)$.

Majority, 723 (92\%), were having knowledge on different types of COVID vaccines. The difference in malefemale was statistically significant $(p<0.001)$. Half of the participants, 386 (50\%), feel the COVID vaccine will prevent the infection among the vaccinated, followed by face mask $188(24 \%)$ and social distancing $125(16 \%)$ to prevent the COVID infection. Most of the participants, $520(66 \%)$, informed that two doses of vaccine per person are required to get the Immunity against the COVID-19 to prevent the mortality. The difference between males and females was statistically not significant $(\mathrm{p}>0.42)$ Further details have been provided in Table 3 .

Out of the 782 participants, 354 (45\%) were willing to take the vaccine, and nearly one-quarter of the participants, 345 (44\%), were still in a dilemma; (almost equal proportion of males and females were answered no to vaccination) they were willing to receive vaccine after received by most of the population, maybe they want to 
Table I Distribution of Respondents Based on Socio-Demographic Details $(n=782)$

\begin{tabular}{|c|c|c|c|c|c|c|c|c|}
\hline \multicolumn{2}{|c|}{ Socio-Demographic Information } & \multicolumn{6}{|c|}{ Gender } & \multirow[t]{3}{*}{$\mathrm{p}=$ value } \\
\hline & & \multicolumn{2}{|c|}{ Male } & \multicolumn{2}{|c|}{ Female } & \multicolumn{2}{|c|}{ Total } & \\
\hline & & Count & $\%$ & Count & $\%$ & Count & $\%$ & \\
\hline \multirow[t]{2}{*}{ Nationality } & Non-Saudi & 24 & 80 & 6 & 20 & 30 & 100 & $>0.074 \mathrm{NS}^{*}$ \\
\hline & Saudi & 482 & 64 & 270 & 36 & 752 & 100 & \\
\hline \multirow[t]{4}{*}{ Age Group } & $<20$ & 26 & 90 & 3 & 10 & 29 & 100 & $<0.0001 \mathrm{~S}^{* *}$ \\
\hline & $20-39$ & 353 & 72 & 135 & 28 & 488 & 100 & \\
\hline & $40-59$ & 118 & 46 & 138 & 54 & 256 & 100 & \\
\hline & $>60$ & 9 & 100 & 0 & 0 & 9 & 100 & \\
\hline \multirow[t]{3}{*}{ Education } & High School & 60 & 44 & 76 & 56 & 136 & 100 & $<0.0001 \mathrm{~S}^{* *}$ \\
\hline & Graduate & 301 & 68 & 143 & 32 & 444 & 100 & \\
\hline & $\geq$ Postgraduate & 145 & 72 & 57 & 28 & 202 & 100 & \\
\hline \multirow[t]{4}{*}{ Occupation } & Professional & 35 & 66 & 18 & 34 & 53 & 100 & $<0.0001 \mathrm{~S}^{* *}$ \\
\hline & Employed & 284 & 67 & $14 \mid$ & 33 & 425 & 100 & \\
\hline & Un employee & 38 & 26 & 111 & 74 & 149 & 100 & \\
\hline & Student & 149 & 96 & 6 & 4 & 155 & 100 & \\
\hline \multirow[t]{3}{*}{ Marital status } & Married & 312 & 57 & 237 & 43 & 549 & 100 & $<0.0001 \mathrm{~S}^{* *}$ \\
\hline & Single & 190 & 83 & 38 & 17 & 228 & 100 & \\
\hline & Widow/D & 4 & 80 & I & 20 & 5 & 100 & \\
\hline \multirow[t]{2}{*}{ Rural/Urban } & Rural & 71 & 72 & 28 & 28 & 99 & 100 & $>0.118 \mathrm{NS}^{*}$ \\
\hline & Urban & 435 & 64 & 248 & 36 & 683 & 100 & \\
\hline
\end{tabular}

Abbreviations: *NS, not significant; *S, significant.

wait and watch the vaccination progress, observe the side effects and efficacy of the vaccine, the vaccine hesitancy difference in males and females was statistically significant $(\mathrm{p}<0.0001)$. Most of the participants, 370 (47\%) preferring to take USA-manufactured vaccine followed by Saudi Arabia-prepared vaccine 217 (28\%), were willing to accept significant number of females were opting for their nation-made vaccine than males. This difference was statistically significant, and the details have been provided in Table 4.

Naturally like other studies, this study also observed higher education participants were more the knowledge of COVID-19. Almost all education-level participants are equally willing for the vaccine. There is no statistically significant difference between these groups $(\mathrm{p}>0.05)$. Lower educated people preferred the native country-manufactured vaccine, whereas higher educated people are chosen for the USA-based vaccine. Fear of side effects, doubt of vaccine efficacy and safety worries were high in the higher educated participants than lower educated. This difference was statistically significant $(\mathrm{p}<0.001)$; the details have been provided in Table 5 .
Many of the participants, 349 (44.6\%) [female 163 (59\%) and male $186(37 \%)$ ], were opined that if enough evidence on vaccine safety and efficacy were established, people will accept the vaccine without much hesitance. Nearly half $(42 \%)$ of the participants [245 (48\%) men and $90(33 \%)$ women] were expressed their view that if the government forces by implementing a law, many will accept the vaccine. Details have been provided in Figure 1.

This study observed that education is the main potential factor having most influence on the vaccine acceptance, followed by the age of the individuals, those with chronic diseases afraid of side effects and doubt on the efficacy of the vaccine - the potential influential factors on the hesitance of the vaccine. Details have been provided in Table 6 .

\section{Discussion}

Herd immunity is one of the essential aspects of containing any diseases. To get herd immunity, one fundamental weapon is the vaccine. Despite the benefits of vaccination, this health-protecting tool is facing many obstacles nationally and internationally. This study aimed to understand 
Table 2 Distribution of Study Group-Based on Socio-Demographic Profile with the Willingness to Receive the Vaccine

\begin{tabular}{|c|c|c|c|c|c|c|c|c|c|c|c|c|}
\hline \multicolumn{2}{|l|}{ Parameter } & \multicolumn{11}{|c|}{ Willing to Take the Vaccine } \\
\hline & & \multicolumn{2}{|c|}{ Absolutely No } & \multicolumn{2}{|c|}{ May be no } & \multicolumn{2}{|c|}{ Maybe Yes } & \multicolumn{2}{|c|}{ Absolutely Yes } & \multicolumn{2}{|c|}{ Total } & \multirow{2}{*}{$\begin{array}{c}\mathrm{p} \text {-value } \\
\mathrm{p}<0.05 \mathrm{~S}^{* *}\end{array}$} \\
\hline & & Count & $\%$ & Count & $\%$ & Count & $\%$ & Count & $\%$ & Count & $\%$ & \\
\hline \multirow[t]{2}{*}{ Nationality } & Non-Saudi & I & 3 & 14 & 47 & 5 & 17 & 10 & 33 & 30 & 100 & $>0.12 \mathrm{NS}^{*}$ \\
\hline & Saudi & 82 & 11 & 162 & 22 & 164 & 22 & 344 & 46 & 752 & 100 & \\
\hline \multirow[t]{2}{*}{ Gender } & Female & 31 & 11 & 93 & 34 & 58 & 21 & 94 & 34 & 276 & 100 & $<0.0001 \mathrm{~S}^{* *}$ \\
\hline & Male & 52 & 10 & 83 & 16 & 111 & 22 & 260 & 51 & 506 & 100 & \\
\hline \multirow[t]{4}{*}{ Age Group } & $<20$ & 5 & 17 & 7 & 24 & 6 & 21 & 11 & 38 & 29 & 100 & $<0.007 \mathrm{~S}^{* *}$ \\
\hline & $>60$ & 1 & 11 & 0 & 0 & 0 & 0 & 8 & 89 & 9 & 100 & \\
\hline & $20-39$ & 50 & 10 & 93 & 19 & 106 & 22 & 239 & 49 & 488 & 100 & \\
\hline & $40-59$ & 27 & 11 & 76 & 30 & 57 & 22 & 96 & 38 & 256 & 100 & \\
\hline \multirow[t]{3}{*}{ Education } & $<$ High school & 14 & 10 & 32 & 24 & 24 & 18 & 66 & 49 & 136 & 100 & $>0.39 \mathrm{NS}^{*}$ \\
\hline & Graduate & 51 & 11 & 99 & 22 & 107 & 24 & 187 & 42 & 444 & 100 & \\
\hline & >Postgraduate & 18 & 9 & 45 & 22 & 38 & 19 & 101 & 50 & 202 & 100 & \\
\hline \multirow[t]{4}{*}{ Occupation } & Employed & 41 & 10 & 99 & 23 & 95 & 22 & 190 & 45 & 425 & 100 & $<0.0001 \mathrm{~S}^{* *}$ \\
\hline & Professional & 4 & 8 & 19 & 36 & 19 & 36 & 11 & 21 & 53 & 100 & \\
\hline & Student & 20 & 13 & 20 & 13 & 38 & 25 & 77 & 50 & 155 & 100 & \\
\hline & Un Employed & 18 & 12 & 38 & 26 & 17 & $\mathrm{II}$ & 76 & 51 & 149 & 100 & \\
\hline \multirow[t]{3}{*}{ Marital status } & Married & 47 & 9 & $|5|$ & 28 & 101 & 18 & 250 & 46 & 549 & 100 & $<0.001 \mathrm{~S}^{* *}$ \\
\hline & Single & 34 & 15 & 25 & 11 & 68 & 30 & 101 & 44 & 228 & 100 & \\
\hline & Widow/D & 2 & 40 & 0 & 0 & 0 & 0 & 3 & 60 & 5 & 100 & \\
\hline \multirow[t]{2}{*}{ Rural/Urban } & Rural & 4 & 4 & 19 & 19 & 21 & 21 & 55 & 56 & 99 & 100 & $<0.05 \mathrm{~S}^{* *}$ \\
\hline & Urban & 79 & 12 & 157 & 23 & 148 & 22 & 299 & 44 & 683 & $100 \%$ & \\
\hline \multirow[t]{3}{*}{ Chronic Diseases } & Yes & 29 & 21 & 60 & 43 & 45 & 32 & 6 & 4 & 140 & 100 & $<0.001 \mathrm{~S}^{* *}$ \\
\hline & No & 54 & 8 & 294 & 46 & 124 & 19 & 170 & 26 & 642 & 100 & \\
\hline & Total & 83 & 11 & 354 & 45 & 169 & 22 & 176 & 23 & 782 & 100 & \\
\hline \multirow[t]{2}{*}{ H/o Allergy } & Yes & 3 & 30 & 2 & 20 & 3 & 30 & 2 & 20 & 10 & 100 & $>0.146 \mathrm{NS}^{*}$ \\
\hline & No & 80 & 10 & 174 & 23 & 166 & 22 & 352 & 46 & 772 & 100 & \\
\hline \multirow[t]{2}{*}{ H/o COVID } & Yes & 18 & 12 & 26 & 17 & 35 & 22 & 77 & 49 & 156 & 100 & $>0.273 \mathrm{NS}^{*}$ \\
\hline & No & 65 & 10 & 150 & 24 & 134 & 21 & 277 & 44 & 626 & 100 & \\
\hline \multirow[t]{9}{*}{ Blood group } & A Positive & 34 & 16 & 37 & 17 & 54 & 25 & 90 & 42 & 215 & 100 & $<0.0001 \mathrm{~S}^{* * *}$ \\
\hline & A Negative- & I & 2 & 0 & 0 & 15 & 29 & 35 & 69 & 51 & 100 & \\
\hline & B Positive & 0 & 0 & 2 & 5 & 3 & 7 & 36 & 88 & 41 & 100 & \\
\hline & B-Negative & 8 & 67 & 0 & 0 & 4 & 33 & 0 & 0 & 12 & 100 & \\
\hline & O Positive & 32 & 9 & 109 & 31 & 66 & 19 & 142 & $4 I$ & 349 & 100 & \\
\hline & O Negative & 4 & II & II & 31 & 7 & 20 & 13 & 37 & 35 & 100 & \\
\hline & AB Positive & 0 & 0 & I & 9 & 4 & 36 & 6 & 55 & 11 & 100 & \\
\hline & AB Negative & 1 & 5 & 10 & 48 & 10 & 48 & 0 & 0 & 21 & 100 & \\
\hline & Do not know & 3 & 6 & 6 & 13 & 6 & 13 & 32 & 68 & 47 & 100 & \\
\hline \multirow[t]{3}{*}{ Disability } & Locomotor & 2 & 8 & 23 & 92 & 0 & 0 & 0 & $0 \%$ & 25 & 100 & $<0.001 \mathrm{~S}^{* *}$ \\
\hline & No & 81 & 11 & 153 & 20 & 169 & 22 & 350 & 46 & 753 & 100 & \\
\hline & Visual & 0 & 0 & 0 & 0 & 0 & 0 & 4 & 100 & 4 & 100 & \\
\hline
\end{tabular}

Abbreviations: *NS, not significant; *S, significant. 
Table 3 Distribution of Sample Based on Gender and Knowledge About COVID Vaccine

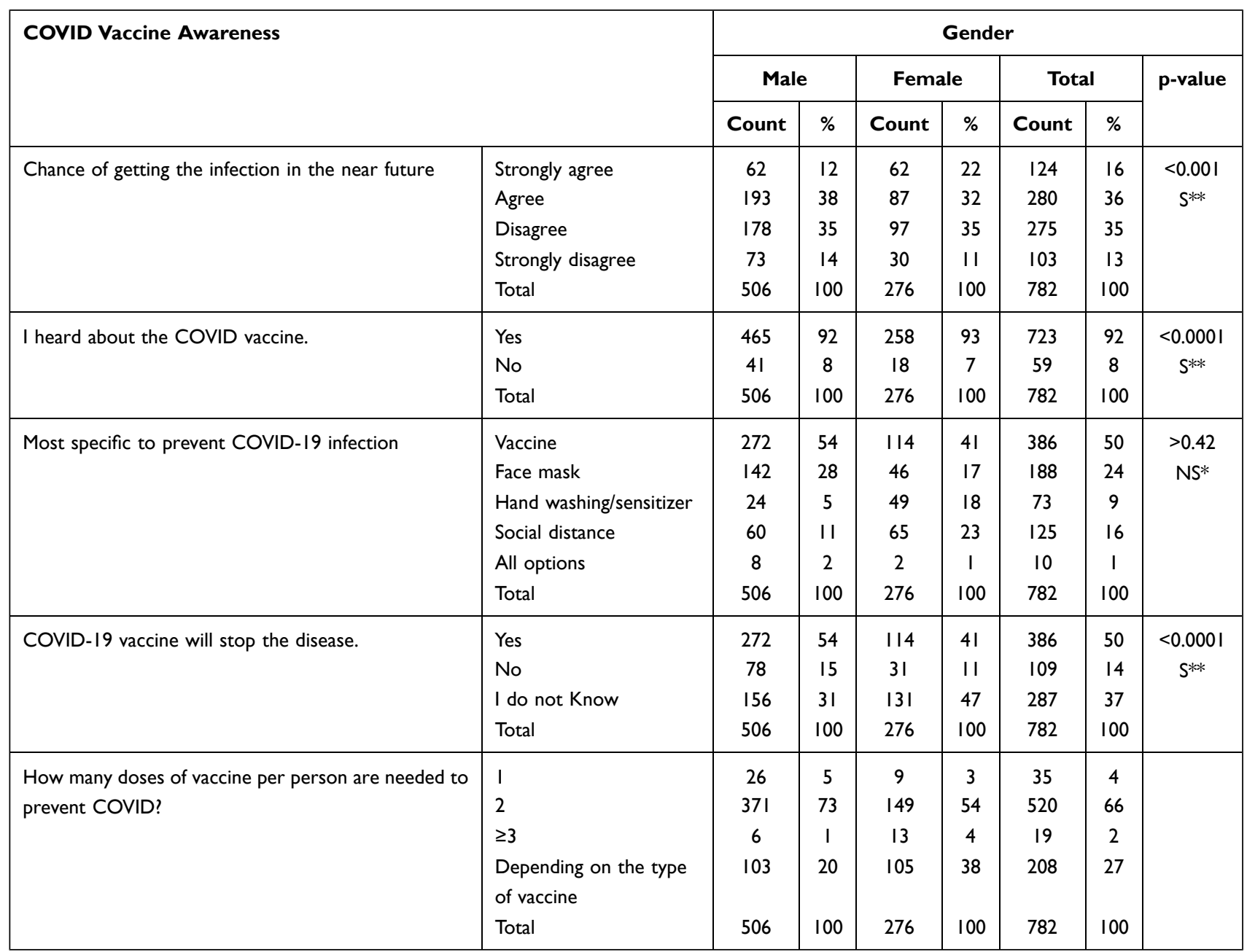

Abbreviations: $*$ NS, not significant; $* S$, significant.

the contextual human behaviour, which influences the acceptance of vaccination among the population. ${ }^{13}$ The behavioural determinants of vaccine acceptance and hesitancy play a crucial role in fighting with COVID-19 pandemic.

This study was conducted among adults aged between 18 years and above, because currently, the vaccine is available for 18 years and above only; we received responses up to 80 years. A similar study conducted by Sharun et al in India also found a similar age group. ${ }^{12}$ Among the study subjects, men (64.7\%) were outnumbered than women $(35.3 \%)$. Sharun et al also found similar results. In this study, $82.5 \%$ of the participants were either graduates or postgraduates and above. These results align with Sharun et al study conducted in India and Linda Thunstrom et al in the USA.
Although several studies are being conducted all around the world, this study observed that vaccine acceptance is $67 \%$, which is lesser than the results obtained from similar studies conducted in the USA ${ }^{14}$ Thunstrom et al reported $80 \%$ of the general population accepted to get vaccinated, and another study conducted by ${ }^{15} \mathrm{Fu}$ et al, in China, found that $72.5 \%$ of the health care workers accepted to get vaccinated. This study reported that vaccine acceptance among the participants was lower, but it is in alignment with the studies of South Africa (64\%), Russia (54\%), and France $(59 \%)^{16}$ IPSOS, 2020. It is important to note that COVID-19 vaccine hesitancy may not be purely attributable to people's behaviour and attitude towards vaccines; in general, this might be fasttracked approval, novel techniques used for the development of COVID-19 vaccine before establishing enough 
Table 4 Distribution of Sample Based on Gender vs Vaccine Acceptance and Its Barriers

\begin{tabular}{|c|c|c|c|c|c|c|c|c|}
\hline & & \multicolumn{6}{|c|}{ Gender } & \multirow[b]{3}{*}{ p-value } \\
\hline & & \multicolumn{2}{|c|}{ Male } & \multicolumn{2}{|c|}{ Female } & \multicolumn{2}{|c|}{ Total } & \\
\hline & & Count & $\%$ & Count & $\%$ & Count & $\%$ & \\
\hline \multirow[t]{5}{*}{ Willing to take the vaccine? } & Absolutely yes & 260 & 51 & 94 & 34 & 354 & 45 & $<0.0001$ \\
\hline & Maybe yes & 111 & 22 & 58 & 21 & 169 & 22 & $S^{* *}$ \\
\hline & May be no & 83 & 16 & 93 & 34 & 176 & 22 & \\
\hline & Absolutely no & 52 & 10 & 31 & 11 & 83 & 11 & \\
\hline & Total & 506 & 100 & 276 & 100 & 782 & 100 & \\
\hline \multirow{7}{*}{$\begin{array}{l}\text { Which country-manufactured } \\
\text { vaccine preferred? }\end{array}$} & Saudi Arabia & 122 & 24 & 95 & 34 & 217 & 28 & $<0.0001$ \\
\hline & USA & 282 & 56 & 88 & 32 & 370 & 47 & $\mathrm{~S}^{* *}$ \\
\hline & China & 17 & 3 & 38 & 14 & 55 & 7 & \\
\hline & Russia & 17 & 3 & 19 & 7 & 36 & 5 & \\
\hline & India & 15 & 3 & 3 & I & 18 & 2 & \\
\hline & Other & 53 & 10 & 33 & 12 & 86 & II & \\
\hline & Total & 506 & 100 & 276 & 100 & 782 & 100 & \\
\hline \multirow{5}{*}{$\begin{array}{l}\text { Intended to take vaccine after } \\
\text { received by many people? }\end{array}$} & Strongly agree & 167 & 33 & 113 & 41 & 280 & 36 & $>0.134$ \\
\hline & Agree & 136 & 27 & 59 & 21 & 195 & 25 & NS* \\
\hline & Disagree & 130 & 26 & 67 & 24 & 197 & 25 & \\
\hline & Strongly not agree & 73 & 14 & 37 & 13 & 110 & 14 & \\
\hline & Total & 506 & 100 & 276 & 100 & 782 & 100 & \\
\hline \multirow{6}{*}{$\begin{array}{l}\text { Reasons for not intended to the } \\
\text { vaccine }(n=428)\end{array}$} & Fear of injection & 10 & 2 & 5 & 3 & 15 & 4 & $<0.0001$ \\
\hline & Fear of side effects & 55 & II & 57 & 31 & 112 & 26 & $S^{* *}$ \\
\hline & Not sure of Vaccine efficacy and safety & 93 & 18 & 70 & 38 & 163 & 38 & \\
\hline & $\begin{array}{l}\text { The vaccine does not require because I am } \\
\text { healthy and follow instructions }\end{array}$ & 36 & 7 & 16 & 9 & 52 & 12 & \\
\hline & Not to answer & 52 & 10 & 34 & 19 & 86 & 20 & \\
\hline & Total & 246 & 100 & 182 & 100 & 428 & 100 & \\
\hline \multirow{3}{*}{$\begin{array}{l}\text { Preferring different forms of a } \\
\text { vaccine }\end{array}$} & Yes & 287 & 56 & $|4|$ & 50 & 428 & 54 & $>0.110$ \\
\hline & No & 219 & 44 & 135 & 50 & 354 & 46 & NS* \\
\hline & Total & 506 & 100 & 276 & 100 & 782 & 100 & \\
\hline
\end{tabular}

Abbreviations: *NS, not significant; *S, significant.

evidence of vaccine safety and not enough measures to create the awareness about the vaccine in the community. ${ }^{17}$

As per the " $3 \mathrm{Cs}$ " model, statement of MacDonald, ${ }^{6}$ vaccine hesitancy toward vaccination might be the influencing factors like confidence, complacency, and convenience. The most common reason for the vaccine hesitancy was lack of confidence in the vaccine efficacy, and safety and fear of side effects are the major barriers prevailing among the study subjects. A similar study conducted by Shimaa M. Saied in Egypt also observed similar findings.${ }^{18}$ This hesitancy might be due to the fast-track approval of vaccines or widespread conspiracy theory may be the reason for the vaccine hesitance. ${ }^{7}$ Another major barrier to COVID-19 vaccination is spreading the misinformation/ falsified information very rapidly via various social media platforms globally. ${ }^{19}$

Suggesting ways to improve vaccine acceptance, this study noticed that more people are concerned about the safety and efficacy of the vaccine. Based on the overall response, if more studies are conducted to evaluate the effectiveness and safety of vaccines, many were expressed if the substantial evidence was available for the security, and the government made compulsion for vaccination by linking the job or travel welfare schemes. Similar findings were observed by the different studies conducted by Sharun et al in India ${ }^{12}$ and Linda Thunstrom et al in the USA. $^{14}$ 
Table 5 Distribution of Sample Based on Education vs Vaccine Acceptance and Its Barriers

\begin{tabular}{|c|c|c|c|c|c|c|c|c|c|c|}
\hline & & \multicolumn{8}{|c|}{ Education } & \multirow[b]{3}{*}{ p-value } \\
\hline & & \multicolumn{2}{|c|}{$\leq$ High School } & \multicolumn{2}{|c|}{ Graduate } & \multicolumn{2}{|c|}{$\geq$ Postgraduate } & \multicolumn{2}{|c|}{ Total } & \\
\hline & & Count & $\%$ & Count & $\%$ & Count & $\%$ & Count & $\%$ & \\
\hline \multirow[t]{5}{*}{ Willing to take the vaccine? } & Absolutely yes & 66 & 49 & 187 & 42 & 101 & 50 & 354 & 45 & $>0.39$ \\
\hline & Maybe yes & 24 & 18 & 107 & 24 & 38 & 19 & 169 & 22 & NS* \\
\hline & may be no & 32 & 24 & 99 & 22 & 45 & 22 & 176 & 23 & \\
\hline & Absolutely No & 14 & 10 & 51 & 11 & 18 & 9 & 83 & 11 & \\
\hline & Total & 136 & 100 & 444 & 100 & 202 & 100 & 782 & 100 & \\
\hline \multirow{7}{*}{$\begin{array}{l}\text { Which country-manufactured } \\
\text { vaccine preferred? }\end{array}$} & Saudi Arabia & 45 & 33 & $|5|$ & 34 & 21 & 10 & 217 & 28 & $<0.0001$ \\
\hline & USA & 40 & 29 & 173 & 39 & 157 & 78 & 370 & 47 & $\mathrm{~S}^{* *}$ \\
\hline & China & 3 & 2 & 47 & II & 5 & 2 & 55 & 7 & \\
\hline & Russia & 5 & 4 & 31 & 7 & 0 & 0 & 36 & 5 & \\
\hline & INDIA & 2 & I & 2 & 0 & 14 & 7 & 18 & 2 & \\
\hline & Other & 41 & 30 & 40 & 9 & 5 & 2 & 86 & II & \\
\hline & Total & 136 & 100 & 444 & 100 & 202 & 100 & 782 & 100 & \\
\hline \multirow{5}{*}{$\begin{array}{l}\text { Intended to take vaccine after } \\
\text { received by many people }\end{array}$} & Agree & 28 & 21 & 90 & 20 & 77 & 38 & 195 & 25 & $<0.0001$ \\
\hline & Disagree & 30 & 22 & 119 & 27 & 48 & 24 & 197 & 25 & $\mathrm{~S}^{* *}$ \\
\hline & Strongly Agree & 60 & 44 & 170 & 38 & 50 & 25 & 280 & 36 & \\
\hline & Strongly Not Agree & 18 & 13 & 65 & 15 & 27 & 13 & 110 & 14 & \\
\hline & Total & 136 & 100 & 444 & 100 & 202 & 100 & 782 & 100 & \\
\hline \multirow[t]{6}{*}{ Reasons for not taking } & Fear of injection & 5 & 7 & 10 & 4 & 0 & 0 & 15 & 4 & $<0.0001$ \\
\hline & Fear of side effects & 25 & 36 & 61 & 24 & 26 & 26 & 112 & 26 & $S^{* *}$ \\
\hline & Not sure of Vaccine & 17 & 24 & 106 & 41 & 40 & 40 & 163 & 38 & \\
\hline & $\begin{array}{l}\text { I am healthy and follow } \\
\text { instructions }\end{array}$ & 15 & 21 & 37 & 14 & 0 & 0 & 52 & 12 & \\
\hline & Not to answer & 8 & II & 43 & 17 & 35 & 35 & 86 & 20 & \\
\hline & Total & 70 & 100 & 257 & 100 & 101 & 100 & 428 & 100 & \\
\hline \multirow{3}{*}{$\begin{array}{l}\text { Preferring different forms of } \\
\text { vaccine }\end{array}$} & Yes & 93 & 68 & 241 & $54 \%$ & 90 & 45 & 424 & 54 & $<0.0001$ \\
\hline & No & 43 & 32 & 203 & 46 & 112 & 55 & 358 & 46 & $S^{*}$ \\
\hline & Total & 136 & 100 & 444 & 100 & 202 & 100 & 782 & 100 & \\
\hline
\end{tabular}

Abbreviations: *NS, not significant; *S, significant.

\section{Limitations}

This study was conducted in a restricted environment. Since COVID-19 restrictions were imposed and it was difficult to recruit directly the study subjects, the snowball sampling technique was used. The authors have very little control on the recruitment of the study samples. They may not be representative to the entire target population, but only reach to the known groups, educated people. Large sample size with a more systematic, inclusive sampling method can improve the representativeness and generalizability of the findings.

Another limitation of the present study is the possibility of participants' positive responses. However, as this study was conducted online, participants could answer positively, giving socially accepted, because of online questions, instead of what they were practicing.

Another limitation of the study was the self-administered questionnaire, where responses were recorded electronically by sophisticated methods that senior citizens may not know.

\section{Conclusion}

The findings of the current study can be utilized for planning the vaccination campaigns. This study observed the worries among the participants regarding the safety and efficacy of COVID-19 vaccines. The government must implement appropriate culturally accepted interventional vaccination educational campaigns to remove the beliefs, 


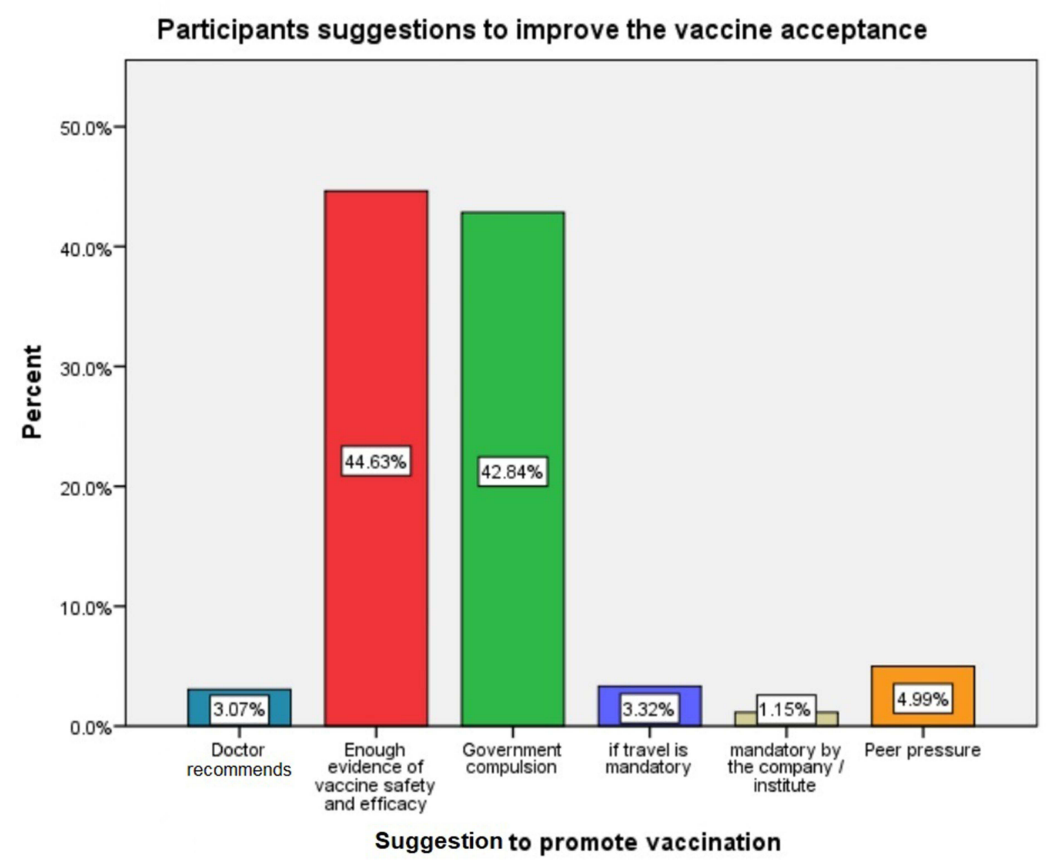

Figure I Study participants suggestion to improve the vaccination coverage.

worries regarding the safety, efficacy, and vaccine side effects of COVID-19 vaccines, which will help to increase vaccine acceptance rates. These concerns may hamper the vaccination program government might think of implementing a law for compulsory vaccine to proceed for educational activities, international travel and tourism centres, etc. Provision of evidence-based information on COVID-19 vaccines and effective initiatives to keep surveillance on social media to fight misinformation/falsified information. Telecast expert group from health professionals and scientists for scientific discussion in social and traditional media and provide evidence on COVID19 vaccine will help the reconstruction of the confidence and trust on vaccine.

Table 6 Multivariate Analysis for the Vaccine Acceptance

\begin{tabular}{|l|c|c|c|}
\hline \multicolumn{4}{|l|}{ Adherence of COVID-19 Vaccination } \\
\hline Covariates & Mean Square & F Value & P value \\
\hline Education & 2.066 & 4.591 & 0.033 \\
\hline Non-Adherence of COVID-19 Vaccination \\
\hline Age & 34.024 & 39.381 & 0.001 \\
Diabetes & 5.953 & 6.891 & 0.009 \\
Hypertension & 10.7 .3 & 12.389 & 0.001 \\
Preferring different vaccine & 19.486 & 22.554 & 0.001 \\
\hline
\end{tabular}

More studies on the larger sample are required to get an insight on approval, clearing the worries and willingness for COVID-19 vaccines. This study will help the program planners and administrators formulate efficient strategies to help achieve COVID-19 vaccination above the expected level to establish herd immunity in Saudi Arabia.

\section{Acknowledgments}

The authors expressed their sincere thanks to all the participants in the study. The authors extend their appreciation to the Deanship of Scientific Research at King Khalid University for funding this work through Large Research Group Program number 37-40.

\section{Disclosure}

The authors report no conflicts of interest in this work.

\section{References}

1. Ministry Of Health Saudi Arabia; 2021. Available from: https://www. moh.gov.sa/en/Pages/Default.aspx. Accessed November 9, 2021.

2. Coronavirus disease - answers; 2020. Available from: https://www. who.int/emergencies/diseases/novel-coronavirus-2019/coronavirus-dis ease-answers. Accessed November 9, 2021.

3. Ali MJ, Hanif M, Haider MA, et al. Treatment options for COVID-19: a review. Front Med. 2020;7:480. doi:10.3389/fmed.2020.00480

4. Gadoth A, Halbrook M, Martin-Blais R, et al. Assessment of COVID-19 vaccine acceptance among healthcare workers in Los Angeles. Public Glob Health. 2020. doi:10.1101/2020.11.18.2 0234468 
5. Harapan H, Wagner AL, Yufika A, et al. Acceptance of a COVID-19 vaccine in Southeast Asia: a cross-sectional study in Indonesia. Front Public Health. 2020;8:381. doi:10.3389/fpubh.2020.00381

6. MacDonald NE. Vaccine hesitancy: definition, scope and determinants. Vaccine. 2015;33(34):4161-4164. doi:10.1016/j.vaccine.20 15.04.036

7. Lazarus JV, Ratzan SC, Palayew A, et al. A global survey of potential acceptance of a COVID-19 vaccine. Nat Med. 2020. Available from: http://www.nature.com/articles/s41591-020-1124-9.

8. John R. Kerr, Claudia R. Schneider, Gabriel Recchia, Sarah Dryhurst, Ullrika Sahlin, Carole Dufouil, Pierre Arwidson, Alexandra L. J. Freeman, and Sander van der Linden. Predictors of COVID-19 vaccine acceptance across time and countrie Prepr MedRxiv. 6. Available from: https://www.medrxiv.org/content/10.1101/2020.12.09. 20246439v1.full.pdf. Accessed November 19, 2021.

9. Saudi Arabia social media statistics 2021 (infographics) - GMI blog; 2021. Available from: https:/www.globalmediainsight.com/blog/ saudi-arabia-social-media-statistics/. Accessed November 9, 2021.

10. Padhi BK, Al-Mohaithef M. Determinants of COVID-19 vaccine acceptance in Saudi Arabia: a web-based national survey. medRxiv. 2020. doi:10.1101/2020.05.27.20114413

11. Magadmi RM, Kamel FO. Beliefs and barriers associated with COVID-19 vaccination among the general population in Saudi Arabia. In Review; 2020. Available from: https://www.researchs quare.com/article/rs-48955/v1. Accessed November 9, 2021.

12. Sharun K, Rahman CKF, Haritha CV, Jose B, Tiwari R, Dhama K. COVID-19 vaccine acceptance: beliefs and barriers associated with vaccination among the general population in India. J Exp Biol Agric Sci. 2020;8(Spl-1-SARS-CoV-2):S210-8.
13. Xiao X, Wong RM. Vaccine hesitancy and perceived behavioral control: a meta-analysis. Vaccine. 2020;38(33):5131-5138. doi:10.1016/j.vaccine.2020.04.076

14. Thunstrom L, Ashworth M, Finnoff D, Newbold S. Hesitancy towards a COVID-19 vaccine and prospects for herd immunity. SSRN Electron J. 2020. doi:10.2139/ssrn.3593098

15. Fu C, Wei Z, Pei S, Li S, Sun X, Liu P. Acceptance, and preference for COVID-19 vaccination in health-care workers (HCWs). Epidemiology. 2020. doi:10.1101/2020.04.09.20060103

16. Three in four adults globally say they would get a vaccine for COVID-19. Ipsos MORI; 2021. Available from: https://www.ipsos. com/ipsos-mori/en-uk/three-four-adults-globally-say-they-would-getvaccine-covid-19. Accessed November 9, 2021.

17. Dror AA, Eisenbach N, Taiber S, et al. Vaccine hesitancy: the next challenge in the fight against COVID-19. Eur J Epidemiol. 2020;35 (8):775-779. doi:10.1007/s10654-020-00671-y

18. Saied SM, Saied EM, Kabbash IA, Abdo SAE. Vaccine hesitancy: beliefs and barriers associated with COVID-19 vaccination among Egyptian medical students. J Med Virol. 2021;93(7):4280-4291. doi:10.1002/jmv.26910

19. The role of social media in Covid-19 vaccine disinformation; 2021. Available from: https://www.pharmaceutical-technology.com/fea tures/covid-19-vaccine-disinformation-social-media/. Accessed Nov ember 9, 2021.
Journal of Multidisciplinary Healthcare

\section{Publish your work in this journal}

The Journal of Multidisciplinary Healthcare is an international, peerreviewed open-access journal that aims to represent and publish research in healthcare areas delivered by practitioners of different disciplines. This includes studies and reviews conducted by multidisciplinary teams as well as research which evaluates the results or conduct of such teams or healthcare processes in general. The journal

\section{Dovepress}

covers a very wide range of areas and welcomes submissions from practitioners at all levels, from all over the world. The manuscript management system is completely online and includes a very quick and fair peer-review system. Visit http://www.dovepress.com/testimonials. php to read real quotes from published authors. 